\title{
Continuous perineural catheter local anaesthetic infusions for management of acute pain after lower limb amputation
}

\author{
R. Bentley', M. Parker', I. Baxter', C. Nesbitt', A. Telford'. 'Freeman Hospital, Department of Anaesthesia, Newcastle upon Tyne, United Kingdom.
}

${ }^{2}$ Freeman Hospital, Department of Vascular Surgery, Newcastle upon Tyne, United Kingdom.

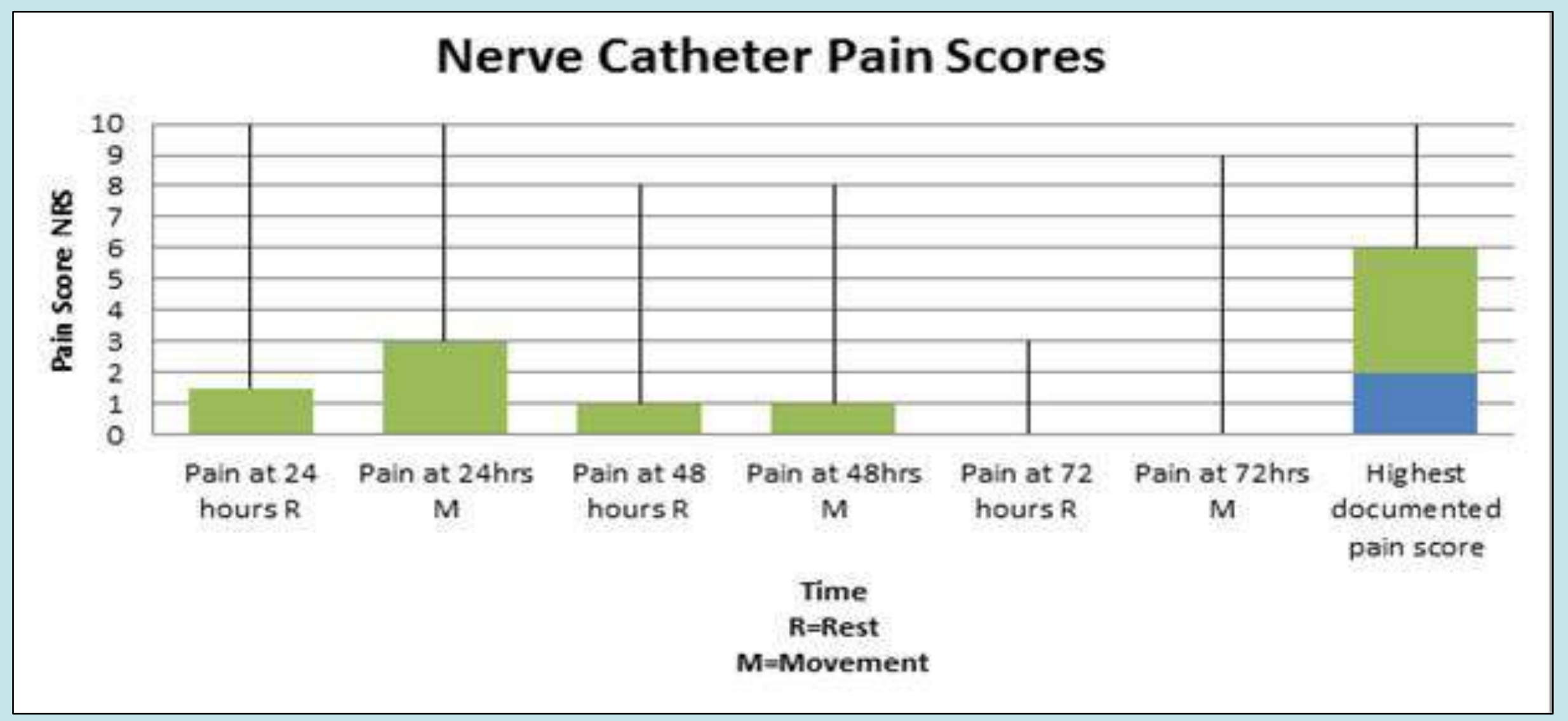

\section{BACKGROUND AND AIMS:}

Lower limb amputation (LLA) is a painful procedure, with postoperative recovery frequently complicated by acute pain!. Poorly controlled acute pain is a risk factor for developing chronic stump pain and phantom limb pain (PLP) ${ }^{2}$. Regional anaesthesia remains the gold standard for care for LLA. We analysed our local practice, where we aim to site ultrasoundguided perineural catheters for all LLAs.

\section{METHODS:}

We performed retrospective analysis of medical notes for patients who had perineural catheters placed for LLA between 2010 and 2017, identified from our hospital's acute pain database. Data collected included type of catheter inserted (femoral or sciatic), pain scores at rest and movement (verbal rating scale 0 to 10 ) at 24, 48 and 72 hours post-op, maximum documented pain score, duration of infusion and reasons for discontinuation. We also evaluated the impact of nerve catheters on post-operative length of stay (LOS), when compared with amputations without perineural LA infusion.

\section{RESULTS:}

85 sets of patient notes were analysed, comprising 33 femoral nerve catheters (FNC) and 52 sciatic nerve catheters (SNC). Mean infusion duration was 5.6 days (FNC) and 6.I days (SNC). Mean post-operative pain scores were low for both Femoral and Sciatic nerve catheters (Table I).We were not able to demonstrate a significant impact on LOS between patients with/without perineural catheters.

\section{Post-operative pain Scores}

\begin{tabular}{|l|c|c|c|}
\hline & $\mathbf{2 4 h}$ & $\mathbf{4 8 h}$ & $\mathbf{7 2 h}$ \\
\hline $\begin{array}{l}\text { SNC mean pain score } \\
\text { at rest (0-10) }\end{array}$ & 1.2 & 0.9 & 0.1 \\
\hline $\begin{array}{l}\text { SNC mean pain score } \\
\text { on movement (0-10) }\end{array}$ & 1.6 & 1.2 & 0.3 \\
\hline $\begin{array}{l}\text { FNC mean pain score } \\
\text { at rest (0-10) }\end{array}$ & 1.3 & 0.5 & 0.1 \\
\hline $\begin{array}{l}\text { FNC mean pain score } \\
\text { on movement (0-10) }\end{array}$ & 1.5 & 0.8 & 0.3 \\
\hline
\end{tabular}

\section{CONCLUSIONS:}

Perineural LA infusions provide effective post-operative analgesia following LLA, facilitating early post-operative mobilisation, improving patient experience and reducing the risk of patients developing chronic pain syndromes.

\section{FUTURE WORK:}

We plan to quantify any benefit in terms of reduced opioid use and prevention of chronic pain in patients undergoing lower limb amputation. 